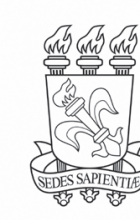

\title{
Artigos
}

\section{Modelagem volumétrica da necromassa lenhosa em floresta manejada e não manejada na Amazônia Central}

\author{
Modeling coarse woody debris volume in logged and unlogged forests in \\ Central Amazon
}

\section{Filipe Campos de Freitas ${ }^{\oplus}{ }^{\oplus}$, Daniel Dantas ${ }^{1}{ }^{\oplus}$, Celso Paulo de Azevedo" ${ }^{\oplus}$, Cintia Rodrigues de Souza" $\oplus$, Natalino Calegario' ${ }^{\oplus}$}

\author{
Universidade Federal de Lavras, Lavras, MG, Brasil \\ "Empresa Brasileira de Pesquisa Agropecuária, Manaus, AM, Brasil
}

\section{RESUMO}

A necromassa lenhosa representa cerca de $20 \%$ do carbono disponível na biomassa acima do solo em florestas amazônicas, entretanto a sua quantificação não é uma atividade comum em estudos florestais. O objetivo deste trabalho foi realizar a modelagem volumétrica da necromassa, a fim de proporcionar uma ferramenta para quantificação desse componente da vegetação. A coleta de dados foi realizada em 15 parcelas permanentes alocadas em floresta sob manejo florestal sustentável e outras 5 em floresta não manejada localizadas no estado do Amazonas, Brasil. Foi realizada a cubagem de troncos e pedaços de troncos de árvores mortas - com diâmetro a partir de $10 \mathrm{~cm}$ - caídos dentro dos limites da parcela. A modelagem foi realizada por meio de regressão não linear (modelo de Schumacher-Hall), Redes Neurais Artificiais (RNA) e Máquina de Vetor de Suporte (MSV). Nessa modelagem, os dados foram divididos em $80 \%$ para ajuste/treinamento e $20 \%$ para teste. Considerou-se como critérios de precisão da modelagem: correlação entre valores estimados e observados, raiz do erro quadrático médio e distribuição gráfica dos resíduos. Foram cubados um total de 1049 troncos ou pedaços de troncos caídos, sendo 848 na área de floresta manejada e 201 na floresta não manejada. Os três métodos testados apresentaram correlação próxima a 1, entre volume observado e estimado. Os menores RMSE\% foram de 33,21\% na floresta manejada (RNA) para a base de ajuste e 22,38\% na floresta não manejada (Schumacher-Hall) para os dados de teste. As RNA apresentaram melhor desempenho durante a etapa de treinamento, todavia não houve boa extrapolação dos seus resultados para a base de teste. O modelo de Schumacher-Hall apresentou o melhor desempenho para as estimativas de volume com os dados da base de teste. A modelagem do volume individual de troncos mortos caídos apresentou dificuldade para minimização dos erros de estimativa devido às características dos dados.

Palavras-chave: Carbono; Madeira morta; Resíduo lenhoso 


\section{ABSTRACT}

Woody necromass represents about $20 \%$ of the carbon available in above-ground biomass in Amazonian forests, however its quantification is not a common activity in forestry studies. The aim of this paper was to modeling necromass volume in order to provide a tool for quantifying this component of vegetation in Amazonian forests. Data collect was carried out in 15 permanent plots allocated in a logged forest and 5 plots in an unlogged forest, both at Amazonas state, Brazil. The volume determination was done for fallen logs and piece of fallen logs from dead tree identified within the boundaries of the plot with a minimum diameter of $10 \mathrm{~cm}$. The modeling was done by non-linear regression (Schumacher-Hall model), training of Artificial Neural Networks (ANN) and Support Vector Machine (SVM) in which the data were divided into $80 \%$ for fitting/training and $20 \%$ for testing. The modeling accuracy was assessed by these following indicators: correlation between estimated and observed volume, root of the mean square error in percentage and residual plot. A total of 1049 logs or pieces of fallen logs from dead trees were measured, 848 in the logged forest area and 201 in the unlogged forest. The three tested methods obtained a correlation between observed and estimated volume close to 1. The lowest RMSE\% were $33,21 \%$ for logged forest (ANN) for training database and 22,38\% for unlgged forest (Schumacher-Hall) for testing database. The ANNs had better performance during the training stage, however there was no good extrapolation of their results to the testing database. The best volume estimates for testing database were obtained from Schumacher-Hall model. The modeling of the individual volume of fallen dead logs presented great difficulty in minimizing the estimation errors due to the data characteristics.

Keywords: Carbon; Dead wood; Necromass

\section{INTRODUÇÃO}

As florestas se apresentam como peças fundamentais na dinâmica das mudanças climáticas globais. Estimativas recentes indicam que florestas tropicais acumulam algo em torno de 230 - 260 Pg de Carbono, o que seria equivalente a 40 - 60\% do carbono presente em toda a vegetação terrestre (PAN et al., 2011; SAATCHI et al., 2011; BACCINI et al., 2012). Nesse contexto, uma atenção diferenciada tem sido dada à Amazônia devido a sua extensão territorial e ao acúmulo de carbono em sua biomassa, representando cerca de 30\% do carbono presente nos ecossistemas terrestres (PIPONIOT et al., 2016).

O Painel Intergovernamental sobre Mudanças Climáticas (IPCC) considera três reservatórios de carbono em florestas: biomassa acima do solo, biomassa de raízes e a necromassa (EGGLESTON et al., 2006). Esse último é composto pelos elementos vegetais mortos nos ecossistemas florestais (árvores inteiras, em pé ou caídas; galhos 
e/ou pedaços de troncos caídos) em estágios variados de decomposição. A biomassa acima do solo (neste caso árvores vivas e mortas) representa cerca de 75\% do carbono armazenado por florestas amazônicas, enquanto a necromassa lenhosa representa cerca de 20\% desse carbono (PALACE et al., 2012). Apesar dessa contribuição, a sua quantificação ainda não é uma atividade comum em estudos florestais em comparação com outros componentes da vegetação, especialmente na Amazônia.

Pesquisas recentes relacionadas à modelagem de variáveis da necromassa tem contemplado o processo de decomposição de resíduos lenhosos no decorrer do tempo (HÉRAULT et al., 2010; FRAVER et al., 2013; RUSSELL et al., 2014). Fraver et al. (2013) enfatizam a necessidade de uma avaliação correta das perdas de massa e carbono decorrentes da decomposição de partes de madeira mortas, algo que vai de encontro à temática discutida no cenário mundial. De acordo com Spies (1998), o volume é a métrica mais escolhida para estudos de estruturas florestais, e, dada a importância de resíduos lenhosos para vários organismos dependentes da madeira morta, o volume é frequentemente usado em estudos da biodiversidade (LASSAUCE et al., 2011; STOKLAND; SIITONEN; JONSSON, 2012). Ratificando a contribuição do estoque volumétrico de necromassa em determinado local, a associação dessa variável com a densidade da madeira morta é o principal método utilizado em pesquisas que visam a análises de massa e/ou carbono presentes nesse componente da vegetação (UMNOUYSIN; SANGTIEAN; POUNGPARN, 2017; MOREIRA; GREGOIRE; COUTO, 2019a; 2019b; SCARANELLO et al., 2019).

Estudos de volumetria de árvores na região amazônica geralmente focam bancos de dados de indivíduos saudáveis - árvores caídas naturalmente, derrubadas ou medição de toras em pátios de estocagem em áreas sob manejo florestal (RIBEIRO; GAMA; MELO, 2014; HIGUCHI et al., 2015; TONINI; BORGES, 2015; AGUIAR et al., 2017). Entretanto, apesar de a necromassa também ser composta por indivíduos recémmortos e em bom estado de conservação, grande parte dos seus componentes se apresentam em algum estágio de decomposição, inicial ou avançado (CRUZ FILHO; 
SILVA, 2009; FREITAS; AZEVEDO; SOUZA, 2019; ZANINOVICH; FONTANA; GATTI, 2016), assim, os indivíduos medidos geralmente não apresentam uniformidade em sua superfície, com grande variação nos diâmetros ao longo da peça. Dessa forma, equações de volume ajustadas com dados de indivíduos sadios podem não ser favoráveis para estimar volume de árvores mortas que apresentem algum grau de decomposição.

Resultados obtidos por Freitas (2017) por meio de regressão linear indicam a possibilidade da modelagem volumétrica de troncos mortos caídos em florestas na Amazônia, os quais apresentaram alta significância e coeficientes de determinação acima de 90\%. Entretanto, com erros padrão excedendo 100\%, e alguns erros individuais de até 300\%, verifica-se a necessidade de buscar alternativas que proporcionem estimativas mais precisas do volume de necromassa. Estudos florestais que aplicaram as técnicas de aprendizagem de máquina mostraram que estas são adequadas para atingir os objetivos da mensuração florestal e em alguns casos com melhores resultados do que a regressão clássica para aplicações em modelagem de variáveis comumente avaliadas em povoamentos florestais, como as relações hipsométricas, volume e biomassa (ARAÚjO et al., 2015; MIGUEL et al., 2015; COSTA FILHO et al., 2019). Com isso, o objetivo deste trabalho foi realizar a modelagem volumétrica da necromassa lenhosa para duas florestas na Amazônia (uma sob manejo florestal; outra sem intervenção) por meio de regressão não linear, redes neurais artificiais e máquinas de vetor de suporte para estimativas de volume individual de troncos e/ou partes de troncos mortos caídos, a fim de possibilitar mecanismos de quantificação desse componente da vegetação em florestas amazônicas.

\section{MATERIAL E MÉTODOS}

\section{1 Área de estudo}

A pesquisa foi desenvolvida em duas áreas diferentes (Figura 1). A primeira é uma floresta sob manejo florestal sustentável pertencente à empresa Mil Madeiras Preciosas, localizada no município de Itacoatiara (Amazonas, Brasil), delimitada pelas 
coordenadas geográficas $02^{\circ} 30^{\prime} \mathrm{S}, 03^{\circ} 00^{\prime} \mathrm{S}, 5^{\circ} 00^{\prime} \mathrm{W}$ e 58³0'W (SOUZA et al., 2017). A empresa realiza suas atividades de exploração florestal desde o ano de 1995, sendo que para este estudo foram utilizados dados de três Unidades de Produção Anuais (UPA) exploradas nos anos de 1996, 1997 e 1998. A segunda área de estudo é uma floresta de 400 hectares, sem nenhum tipo de intervenção silvicultural (não manejada), a qual pertence à Empresa Brasileira de Pesquisa Agropecuária (Embrapa) Amazônia Ocidental, localizada no município de Rio Preto da Eva (Amazonas, Brasil), entre as coordenadas geográficas 2³0'36" S, 2³0'42" S, 6001'29" W e 6001'46" W (SOUZA et al., 2012).

Figura 1 - Áreas de estudo - Floresta manejada: Mil Madeiras Preciosas, Rodovia AM 363, Km 01, Itacoatiara, Amazonas, Brasil; floresta não manejada: Embrapa Amazônia Ocidental, Rodovia BR - 174, KM 938, Rio Preto da Eva, Amazonas, Brasil

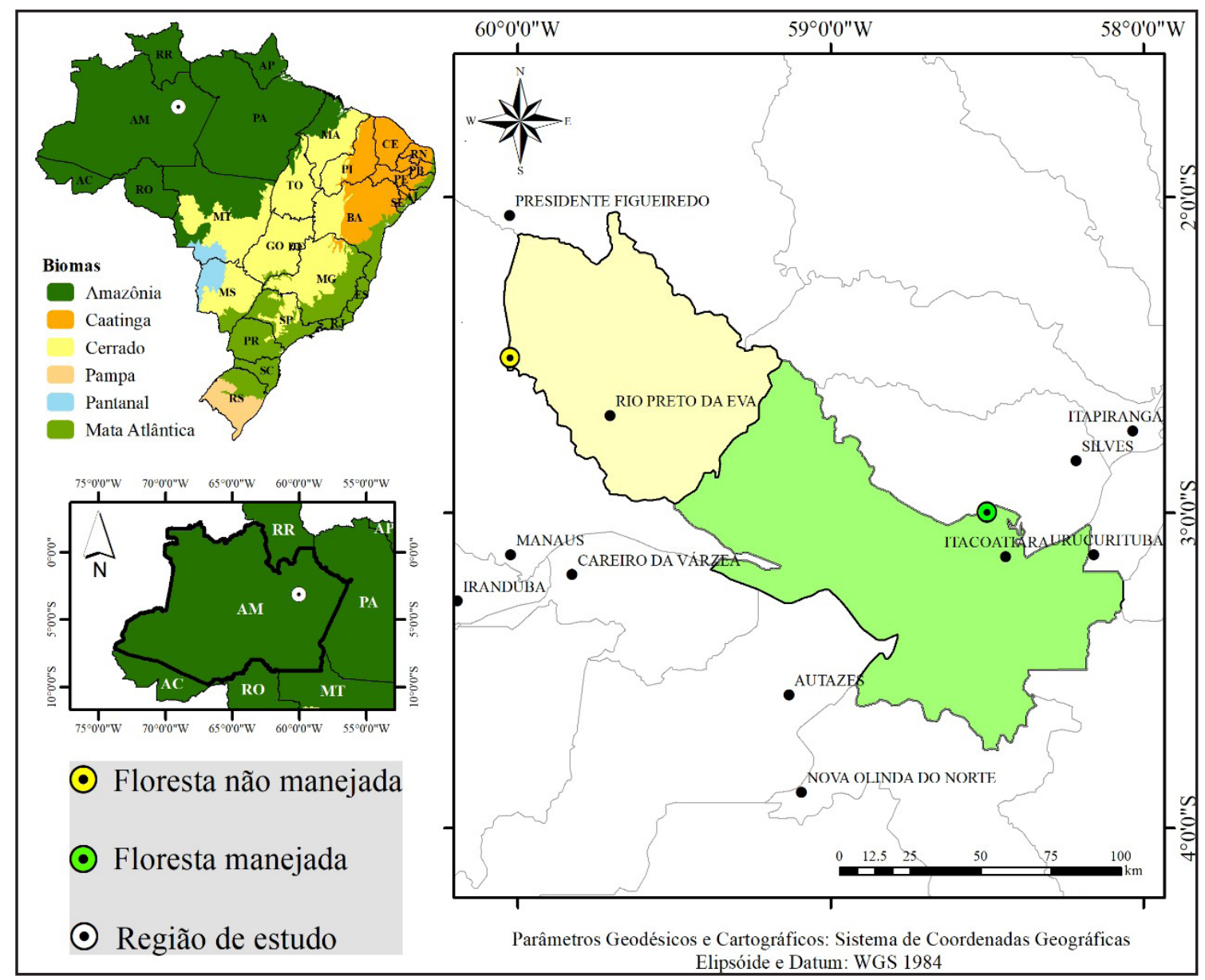

Fonte: Autores (2021) 
As duas áreas de estudo são classificadas como floresta ombrófila densa, localizadas em terra firme, caracterizadas por indivíduos arbóreos de grade porte, com lianas lenhosas e epífitas (IBGE, 2012). O tipo climático da região, pela classificação de Köppen, é "Am" (tropical chuvoso monçônico). A temperatura média anual da região é de $25,3^{\circ} \mathrm{C}$, com precipitação média de $2.624,2 \mathrm{~mm}$ por ano, e umidade relativa do ar média de 86,3\% (ANTONIO, 2017). Os meses mais chuvosos vão de dezembro a maio, e os mais secos, de agosto a novembro. Os solos predominantes na área são o latossolo amarelo com textura muito argilosa e os hidromórficos, cobertos predominantemente pela vegetação da floresta densa de terras baixas, com dossel emergente (IBGE, 2015).

\subsection{Coleta de dados}

A pesquisa utilizou dados de 20 parcelas permanentes alocadas em ambas as áreas (15 na floresta manejada, 5 na floresta não manejada). Cada parcela possui dimensões de 100 m x 100 m, totalizando uma amostragem de 20 hectares.

Foram medidos troncos ou pedaços de troncos caídos cuja base ou toco pudesse ser identificado dentro dos limites da parcela e que possuíssem diâmetro mínimo de $10 \mathrm{~cm}$ em medições a 1,30 m da base do tronco (diâmetro de referência: $D_{1,3}$ ), sem restrições quanto ao comprimento. Nos casos em que o comprimento foi menor que 1,30 m, o diâmetro de referência foi medido no centro da peça. O sentido base-topo foi definido pela observação do decréscimo dos diâmetros ao longo da peça.

Foi realizada cubagem rigorosa dos troncos pela combinação dos métodos de Smalian e Hohenald, com a divisão do tronco em 10 seções de igual comprimento e medição dos diâmetros na base e no topo de cada seção. Esse método foi proposto por Lima (2010) e vem sendo aplicado em estudos na região (GIMENEZ et al., 2015; HIGUICHI et al., 2015; AGUIAR et al., 2017). A medição dos diâmetros ao longo do tronco foi realizada com auxílio de suta, e, o comprimento, com auxílio de trena. Uma vez que o trabalho com necromassa possui dificuldades de medições impostas pelo grau de decomposição, as peças que não apresentaram cerne bem definido, ou sinais 
de madeira maciça, foram desconsideradas na coleta de dados. O volume individual foi calculado aplicando-se a Equação (1):

$$
V=\frac{\pi}{40000} \times\left\{\left(\frac{D_{0}^{2}+D_{10}^{2}}{2}\right)+D_{1}^{2}+\cdots+D_{9}^{2}\right\} \times \frac{L}{10}
$$

Em que: $V$ = volume individual do tronco caído $\left(\mathrm{m}^{3}\right) ; \mathrm{D}_{0}=$ Diâmetro na base do tronco $(\mathrm{cm}) ; \mathrm{D}_{10}=$ Diâmetro no topo do tronco $(\mathrm{cm}) ; \mathrm{D}_{1, \ldots, 9}=$ Diâmetro nas respectivas seções $(\mathrm{cm}) ; \mathrm{L}=$ comprimento do tronco $(\mathrm{m})$.

\subsection{Modelagem volumétrica da necromassa}

Inicialmente foi realizada a modelagem por meio de regressão linear considerando quatro modelos clássicos da literatura florestal (FREITAS, 2017). O resultado desta análise confirmou a possibilidade de ajuste em que os melhores resultados foram obtidos mediante o modelo de Schumacher-Hall linearizado (Tabela 1). Contudo, mesmo para o melhor ajuste, foi encontrado erro padrão (Syx) de 92,42\% para a floresta manejada e 49,81\% para floresta não manejada.

Tabela 1 - Estatística de avaliação do ajuste prévio por regressão linear para volume de necromassa em troncos caídos em floresta manejada e não manejada

\begin{tabular}{|c|c|c|c|c|c|c|}
\hline \multirow{2}{*}{ Modelo } & \multicolumn{3}{|c|}{ Floresta manejada } & \multicolumn{3}{|c|}{ Floresta não manejada } \\
\hline & $\mathbf{F}$ & $R^{2}$ ajust & Syx (\%) & $\mathbf{F}$ & $R^{2}$ ajust & Syx (\%) \\
\hline Berkhout ${ }^{1}$ & $3449,11 * *$ & 79,91 & 115,06 & $779,58 * *$ & 79,56 & 70,66 \\
\hline Schumacher-Hall ${ }^{1}$ & $6855,87 * \star$ & 94,05 & 92,42 & $1554,42 * *$ & 93,95 & 49,81 \\
\hline Spurr & $2109,93 * *$ & 70,87 & 92,72 & $1478,55^{* *}$ & 88,08 & 49,78 \\
\hline Kopezi-Gehrardt & $1154,37 * \star$ & 57,09 & 112,54 & $704,75 * *$ & 77,87 & 67,82 \\
\hline
\end{tabular}

Fonte: Autores (2021)

Em que: ${ }^{1}$ Modelo linearizado; ${ }^{* *}$ Significativo ao nível de 95\% de probabilidade.

Dessa forma, foi proposto o ajuste deste modelo em sua forma não linear juntamente com a aplicação de técnicas de aprendizagem de máquina com intuito de melhorar as estimativas de volume com redução dos erros encontrados. Para tanto, foram adotadas as técnicas de treinamento de Redes Neurais Artificiais (RNA) e Máquina 
de Vetor de Suporte (MVS). As análises foram realizadas no software Rstudio (versão 3.4.1), aplicando os seguintes pacotes: "nls", "neuralnet" e "e1071", para regressão não linear, RNA e MVS, respectivamente.

Os dados foram separados de acordo com a área de estudo: i) floresta manejada; ii) floresta não manejada. Posteriormente, dividiu-se os dados aleatoriamente em duas bases diferentes: uma para ajuste e treinamento dos métodos propostos, outra para teste, com a estimativa de volume individual da necromassa em base de dados diferente da utilizada na modelagem. Desse modo, a base de ajuste foi composta por $80 \%$ dos dados e a base de teste por $20 \%$.

Para o treinamento das RNA e MVS foi realizada a normatização dos dados, a qual consistiu na transformação dos valores reais da base de dados (diâmetro, comprimento e volume, em suas respectivas unidades) em valores entre 0 e 1, por meio da aplicação da Equação (2). Esse procedimento foi adotado devido às funções utilizadas nos algoritmos de treinamento (descritas posteriormente) projetadas para processar dados com valores dentro desse intervalo. Após todo o processamento, os dados foram desnormatizados, para apresentação dos resultados em valores reais e comparação com o ajuste por regressão não linear.

$$
\begin{aligned}
& \mathrm{x}_{\mathrm{n}}=\frac{\mathrm{x}-\mathrm{x}_{\min }}{\mathrm{x}_{\max }-\mathrm{x}_{\min }} \\
& \text { Em que: } \mathrm{x}_{\mathrm{n}}=\text { valor normatizado; } \mathrm{x}=\text { valor original; } \mathrm{x}_{\min }=\text { valor mínimo da variável; } \mathrm{x}_{\max }= \\
& \text { valor máximo da variável. }
\end{aligned}
$$

No treinamento das RNA foi utilizado a arquitetura feedforward de multicamadas (Multilayer Perceptron - MLP). A camada de entrada foi composta por duas variáveis: diâmetro a 1,30 m e comprimento do tronco; apenas uma camada oculta foi adotada, testando entre 1 e 30 neurônios; a camada de saída foi composta pela variável volume do tronco. Para cada quantidade de neurônios na camada oculta foram testadas 10 redes neurais a fim de se alcançar o menor erro possível, dessa forma, ao todo, foram testadas 300 redes neurais artificiais para estimativa do volume de necromassa. 0 algoritmo de aprendizagem utilizado foi o backpropagation, com taxa de aprendizado 
de 0,01 e, como critério de parada, o número máximo de 10.000 ciclos. Após o término do treinamento, foi selecionada a rede com menor erro para comparação com os outros métodos testados e estimativa do volume de necromassa na base de teste.

A construção da MVS se baseou no processo de aprendizagem de máquina supervisionada descrita em detalhes por Haykin (2001) e por Steinwart e Christmann (2008). O algoritmo padrão utilizado foi definido por Chang e Lin (2011). Utilizou-se a função tipo IV de erro, também conhecida como eps-regression, sendo a função Kernel do tipo RBF (função de base radial). A otimização dos parâmetros dos modelos baseou-se no procedimento de determinação do custo mínimo global de uma função com vários mínimos. A média do erro quadrado médio (MSE) foi selecionada como a função custo. A determinação do custo mínimo global foi realizada por análise gráfica em duas etapas e foi avaliada por meio de validação cruzada para otimização global dos parâmetros do modelo MVS, na qual os dados foram divididos em 10 subgrupos, com a proporção de $90 \%$ para treinamento e $10 \%$ para teste. Os parâmetros do modelo final foram aqueles obtidos do modelo que apresentou o menor MSE durante a fase de treinamento.

Para avaliar a qualidade de ajuste dos três métodos testados, foram considerados: correlação entre valores estimados e observados $\left(\mathrm{r}_{\mathrm{Y} \widehat{Y}}\right)$; raiz do erro quadrático médio em porcentagem (RMSE\%), calculados pelas Equações (3) e (4), respectivamente, e distribuição gráfica dos resíduos. Foi considerado o melhor método aquele que apresentou maior valor de $r_{Y \widehat{Y}}$, menor RMSE\% e distribuição de resíduos mais homogênea.

$$
\begin{aligned}
& r_{Y \widehat{Y}}=\frac{\operatorname{Cov}(Y, \widehat{Y})}{\sqrt{S^{2}(Y) S^{2}(\widehat{Y})}} \\
& \text { RMSE\% }=100 \times \bar{Y}^{-1} \sqrt{n^{-1} \sum_{i=1}^{n}\left(Y_{i}-\widehat{Y}_{i}\right)^{2}}
\end{aligned}
$$

Em que: $\operatorname{Cov}=$ Covariância; $S^{2}=$ Variância da amostra; $\widehat{Y}=$ valores estimados; $\mathrm{Y}=$ valores observados; $\overline{\mathrm{Y}}=$ valor médio; $\mathrm{n}=$ número de observações. 
Para auxiliar na análise e compreensão dos erros obtidos após o processamento dos dados, utilizou-se a correlação de Spearman - por considerar relações não lineares - entre as variáveis aplicadas na modelagem. Também foram selecionados, da base de teste, os troncos com erros individuais de estimativas de volume de necromassa maiores de 50\% para análise do perfil, uma vez que a necromassa nem sempre apresenta um decréscimo natural nos diâmetros ao longo do comprimento.

\section{RESULTADOS E DISCUSSÃO}

Foram medidos um total de 1049 troncos ou partes de troncos caídos de árvores mortas, sendo 848 na área de floresta manejada e 201 na floresta não manejada (Tabela 2). Verifica-se alta variabilidade nos dados, em especial para o volume, com coeficientes de variação entre 104\% e 163\%.

Tabela 2 - Estatística descritiva das variáveis das bases de dados de treino e teste utilizadas na modelagem do volume de troncos caídos

\begin{tabular}{cccccc}
\hline \multirow{2}{*}{ Variável } & & \multicolumn{2}{c}{ Manejada } & \multicolumn{2}{c}{ Não Manejada } \\
\cline { 3 - 6 } & & Treino & Teste & Treino & Teste \\
\hline NI & & $\mathbf{6 7 8}$ & $\mathbf{1 7 0}$ & $\mathbf{1 6 0}$ & $\mathbf{4 1}$ \\
\hline \multirow{3}{*}{ Diâmetro a 1,30 m (cm) } & Máximo & 96,4 & 72,2 & 69 & 44,4 \\
& Médio & 25,47 & 25,68 & 25,69 & 24,41 \\
& CV (\%) & 56,73 & 52,17 & 48,96 & 38,22 \\
\hline \multirow{4}{*}{ Comprimento $(\mathrm{m})$} & Máximo & 25 & 27,6 & 29,1 & 22,2 \\
& Mínimo & 1,1 & 2,2 & 1,4 & 2,9 \\
& Médio & 9,35 & 9,72 & 10,37 & 10,44 \\
& CV (\%) & 53,41 & 50,85 & 46,07 & 43,46 \\
\hline \multirow{3}{*}{ Volume $\left(\mathrm{m}^{3}\right)$} & Máximo & 10,0996 & 4,4718 & 5,5859 & 2,145 \\
& Mínimo & 0,0101 & 0,0247 & 0,0239 & 0,0525 \\
& Médio & 0,6364 & 0,6267 & 0,6164 & 0,5083 \\
& CV (\%) & 162,55 & 130,76 & 149,62 & 104,2 \\
\hline
\end{tabular}

Fonte: Autores (2020)

Em que: $\mathrm{NI}$ = número de toras ou pedaço de toras; $\mathrm{CV}$ = coeficiente de variação. 
Os valores elevados para coeficiente de variação são reflexo da amplitude dos dados coletados, uma vez que o diâmetro mínimo de inclusão foi de $10 \mathrm{~cm} \mathrm{e}$ houve registro de troncos com até $96 \mathrm{~cm}$ e sem limite mínimo ou máximo para coleta do comprimento, proporcionando valores entre 1,10 m e 29,10 m. Para o volume, a variação se torna mais expressiva por considerar a amplitude das duas variáveis anteriores. Na área de floresta manejada, os coeficientes de variação foram maiores, pois há registro de diâmetros superiores a $69 \mathrm{~cm}$ - maior diâmetro medido na floresta não manejada - o que pode explicar o volume mínimo de 0,0101 m³ e máximo de $10,0996 \mathrm{~m}^{3}$.

No treinamento das RNA, o menor erro quadrático médio foi obtido para as redes com 18 e 12 neurônios na camada oculta para floresta manejada e não manejada, respectivamente. No treinamento da MVS, o menor erro quadrático médio foi obtido com os seguintes parâmetros: custo $=1$; gamma $=0,72$; epsilon $=0,31$. Todos os três métodos testados apresentaram correlação próxima de 1 entre os valores observados e estimados tanto para a base de ajuste quanto para a base de teste (Tabela 3).

Tabela 3 - Estatísticas de avaliação dos ajustes dos modelos estatístico e aprendizado de máquina treinados para estimativa do volume de necromassa em troncos caídos em floresta manejada e não manejada na Amazônia Central

\begin{tabular}{|c|c|c|c|c|c|}
\hline \multirow{2}{*}{ Área } & \multirow{2}{*}{ Método } & \multicolumn{2}{|c|}{$r_{Y \widehat{Y}}$} & \multicolumn{2}{|c|}{ RMSE\% } \\
\hline & & Ajuste & Teste & Ajuste & Teste \\
\hline \multirow{3}{*}{ Floresta manejada } & Schumacher e Hall & 0,97 & 0,91 & 34,73 & 55,2 \\
\hline & RNA & 0,98 & 0,91 & 33,21 & 78,2 \\
\hline & MVS & 0,95 & 0,9 & 51,32 & 54,83 \\
\hline \multirow{3}{*}{ Floresta não manejada } & Schumacher e Hall & 0,94 & 0,98 & 51,45 & 22,38 \\
\hline & RNA & 0,98 & 0,92 & 27,92 & 41,7 \\
\hline & MVS & 0,96 & 0,97 & 48,78 & 23,77 \\
\hline
\end{tabular}

Fonte: Autores (2020)

Os menores valores de RMSE\% durante a etapa de ajuste/treinamento foram obtidos com RNA para ambas as áreas: 33,21\% para floresta manejada, 27,92\% para 
floresta não manejada (este abaixo dos outros dois métodos testados). Destaca-se, também, o bom desempenho do modelo de Schumacher-Hall aplicado aos dados da floresta manejada, com RMSE\% (34,73\%) bastante próximo ao das redes. Apesar do melhor desempenho durante o treinamento, as RNA apresentaram os maiores erros quando aplicados os pesos obtidos na estimativa de volume na base de teste. De acordo com Özçelik et al. (2010), esse comportamento pode ser indicativo de overfitting, o qual resulta quando uma rede memoriza exemplos individuais ao invés de tendências no conjunto de dados como um todo. Isso ocorre para as duas áreas em estudo, sendo observado com maior magnitude para a floresta manejada, a qual apresenta maior quantidade de dados e, consequentemente, um aumento do RMSE\%. Para a floresta não manejada, foi observado um comportamento contrário, no qual os valores de RMSE\% reduziram na estimativa de volume para a base de teste. Acreditase que isso tenha ocorrido devido a menor variação das variáveis nesta base de dados (Tabela 2). Para a área de floresta não manejada, os ajustes obtidos com o modelo de Schumacher-Hall e MVS foram bastante semelhantes, com pequena vantagem para o modelo de Schumacher-Hall (considerando o erro na base de teste).

Os gráficos de dispersão dos resíduos são apresentados na Figura 2. Os três métodos utilizados apresentam comportamento semelhante para as duas áreas de estudo. As estimativas com o modelo de Schumacher-Hall foram as que apresentaram melhor uniformidade na distribuição dos erros, enquanto para as RNA há uma tendência de subestimativa do volume da necromassa, o que reforça a ideia de overfitting debatida anteriormente. As estimativas com MVS apresentaram uma tendência de superestimativa para o volume de necromassa em troncos de menores diâmetros.

Higuchi et al. (2015) e Aguiar et al. (2017) obtiveram excelentes ajustes de equações para volume comercial de madeira a partir da amostragem de troncos naturalmente caídos, com Syx\% variando de 2,61\% a 6,59\%. Uma vez que a metodologia utilizada no presente estudo é semelhante, esperava-se que para a necromassa os valores de erro fossem não iguais aos estudos citados, porém bem menores que os apresentados na 
Tabela 2. Apesar dos bons valores de correlação, os valores de RMSE\% e os gráficos de resíduos indicam uma alta taxa de erro nas estimativas. Esses erros mostram a dificuldade de se modelar com precisão o volume de necromassa.

Figura 2 - Distribuição de resíduos das estimativas de volume de necromassa, em troncos caídos, a partir do modelo ajustado de Schumacher-Hall e treinamento de Redes Neurais Artificiais (RNA) e Máquina de Vetor de Suporte (MVS) em floresta manejada e floresta não manejada na Amazônia Central

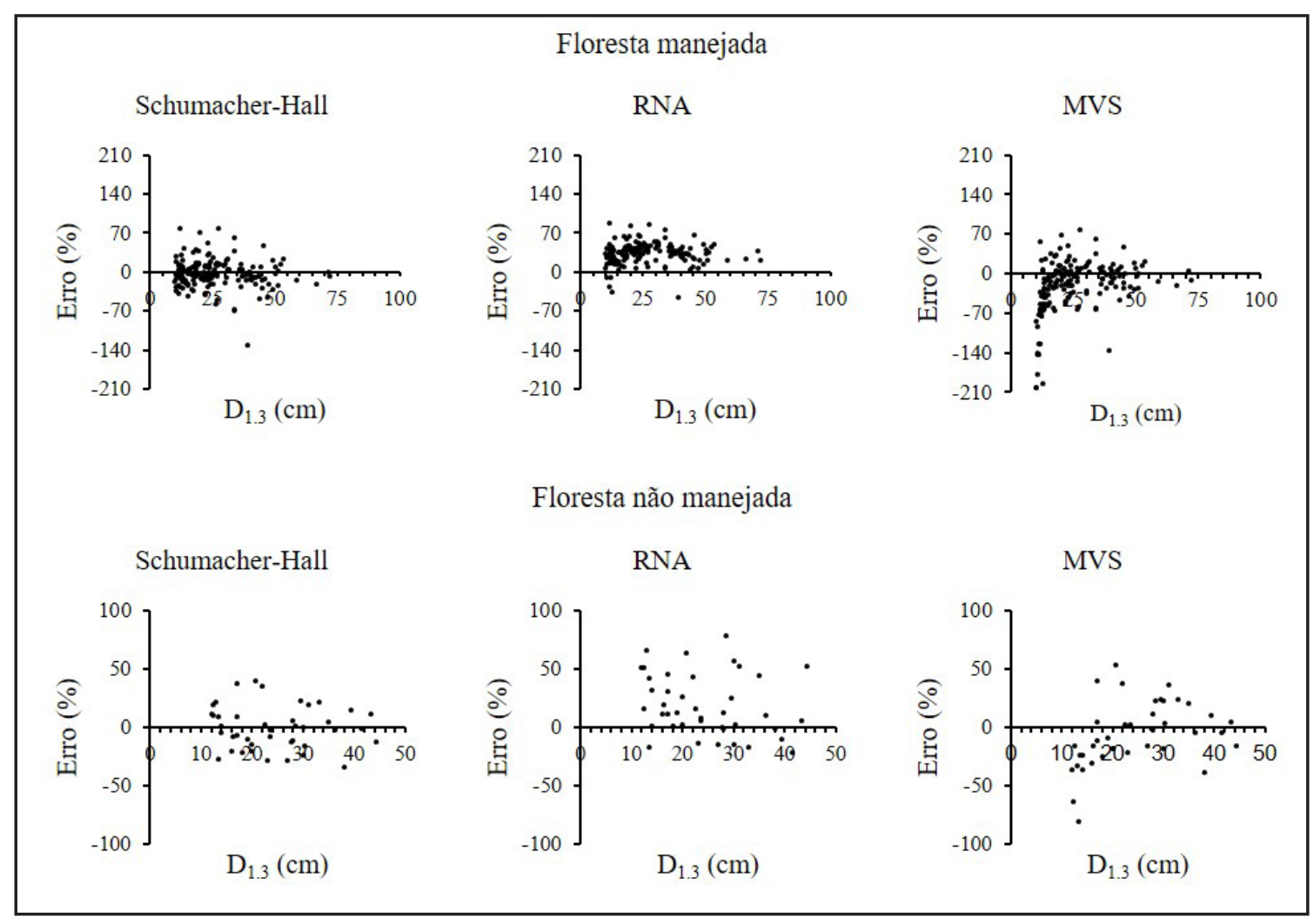

Fonte: Autores (2020)

Comumente na literatura florestal, o limite de erro de $10 \%$ é considerado razoavelmente bom para estimativas de volume de árvores. Os valores apresentados na Tabela 2 de RMSE\% estão de três a oito vezes maiores que esse limite. Uma análise minuciosa dos resíduos mostrou que, na floresta manejada, o método que atingiu a maior quantidade de estimativas com erro abaixo de $10 \%$ foi o de Shumacher-Hall - $41 \%$ dos dados, contra 7\% para as estimativas com RNA e $26 \%$ com MVS. Mesmo 
aumentando o limite de erro para 30\%, o desempenho do modelo de ShumacherHall continua superior, no qual $82 \%$ das estimativas estão dentro desse limite, contra $39 \%$ para as estimativas com RNA e $62 \%$ para MVS. Para a floresta não manejada, foi observado uma menor quantidade de estimativas abaixo dos limites de erros, de 10\% e 30\%, algo já esperado, uma vez que para esta área os valores de RMSE ficaram entre 40\% e 50\%. Com o modelo de Shumacher-Hall foram alcançadas estimativas abaixo de $10 \%$ de erro para $37 \%$ dos dados; para RNA e MVS, esse percentual foi de $27 \%$. Considerando estimativas com erro de até 30\%, o percentual de dados dentro dessa faixa foi de: $90 \%$ com o modelo Shumacher-Hall, 66\% para RNA e $73 \%$ para MVS.

Considerando as características dos dados utilizados (Tabela 2), verifica-se a alta variação (CV\%) tanto nos dados de entrada (diâmetro a 1,30 m, variando entre $38,22 \%$ e $56,73 \%$, e o comprimento entre $43,46 \%$ e $53,41 \%$ ), quanto nos dados de saída (volume entre 104,20\% e 162,55\%). A alta heterogeneidade entre os indivíduos é uma característica comum na floresta amazônica devido à sua ampla diversidade de espécies, ainda mais quando não há agrupamentos por espécies, grupo de espécies, classes diamétricas, entre outros. No entanto, mesmo com alta variação, outros autores encontraram bons ajustes para volume de troncos com o uso da técnica de regressão linear (RIBEIRO; GAMA; MELO, 2014; GIMENEZ et al., 2015; TONINI; BORGES, 2015).

Apesar de a necromassa também ser composta por troncos inteiros, uniformes e em bom estado fitossanitário, a coleta de dados contemplou, além desses descritos, pedaços de troncos caídos, muitas vezes com poucos metros de comprimento. Tais fatos resultaram na ocorrência de troncos com diâmetros elevados na base de dados, mas com comprimentos pequenos, dificultando uma correlação entre essas variáveis, e com o volume calculado (Figura 3).

As melhores correlações são observadas para a floresta manejada devido à maior quantidade de dados, formando uma nuvem mais densa de informações a serem consideradas, dessa forma é possível entender melhor como uma variável se 
correlaciona com outra. Para as duas áreas, as correlações mais fortes são observadas para volume e diâmetro, um comportamento naturalmente esperado entre essas variáveis. Na relação diâmetro/comprimento tem-se uma dificuldade de identificar um padrão de distribuição, linear ou não linear entre os dados, confirmado pelo baixo valor obtido de $\rho$. Com isso, há uma dificuldade maior para os algoritmos de aprendizagem e ajuste estabelecerem valores que representem precisamente essas relações entre variáveis (parâmetros, no caso do modelo de Schumacher-Hall; pesos, no caso das RNA, e vetores de suporte, no caso MVS).

Figura 3 - Correlação de Spearman $(\rho)$ entre as variáveis utilizadas na modelagem do volume de necromassa em troncos caídos na Amazônia Central

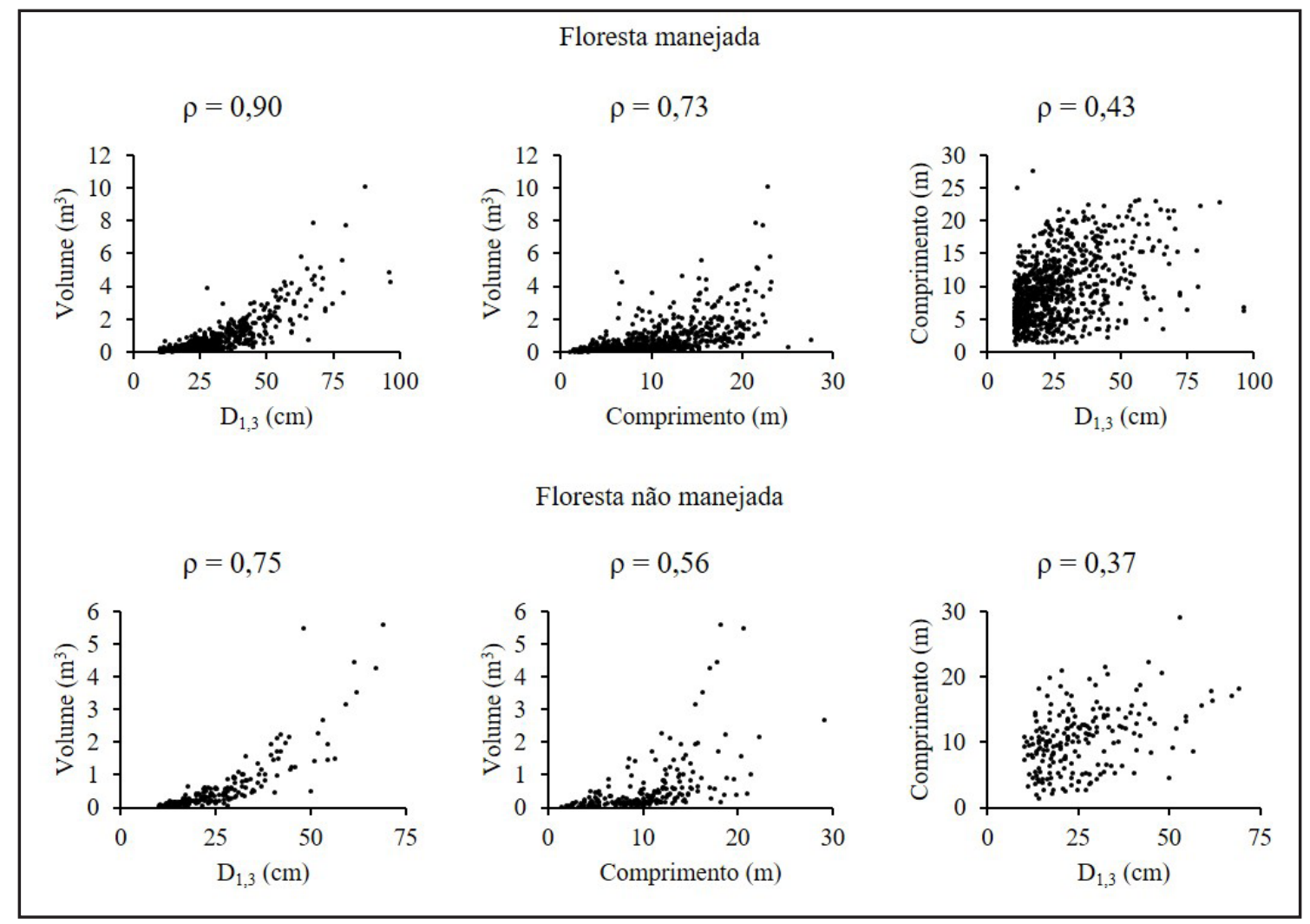

Fonte: Autores (2020)

É comum que estimativas do volume de necromassa considerem a forma das peças como a de uma árvore viva, utilizando-se de equações que consideram essas peças nos formatos geométricos, tradicionalmente associados a troncos de árvores: 
neiloide, paraboloide e/ou cone. Essa forma de estimativa leva em consideração a metodologia de coleta de dados, podendo ser medido apenas um diâmetro na peça ou os diâmetros da base e do topo, além do comprimento (PALACE et al., 2012; RUSSELL et al., 2015). Entretanto, essas metodologias não captam as variações de diâmetros ao longo de uma peça ocasionada pelo processo de decomposição da madeira. Nas duas florestas em análise, Freitas, Azevedo e Souza (2019) verificaram que 55\% do volume de necromassa apresentou alto grau de decomposição na floresta manejada, e 60\% na floresta não manejada. Com isso, há a ocorrência de grandes variações nos diâmetros ao longo do fuste, uma vez que determinado ponto de medição do diâmetro pode estar mais decomposto que outro, portanto, o diâmetro de entrada para estimativas $\left(D_{1,3}\right)$ pode não ser representativo no que se refere ao diâmetro real do tronco (Figura 4).

Figura 4 - Perfil dos troncos com erros individuais de estimativas maiores que 50\%

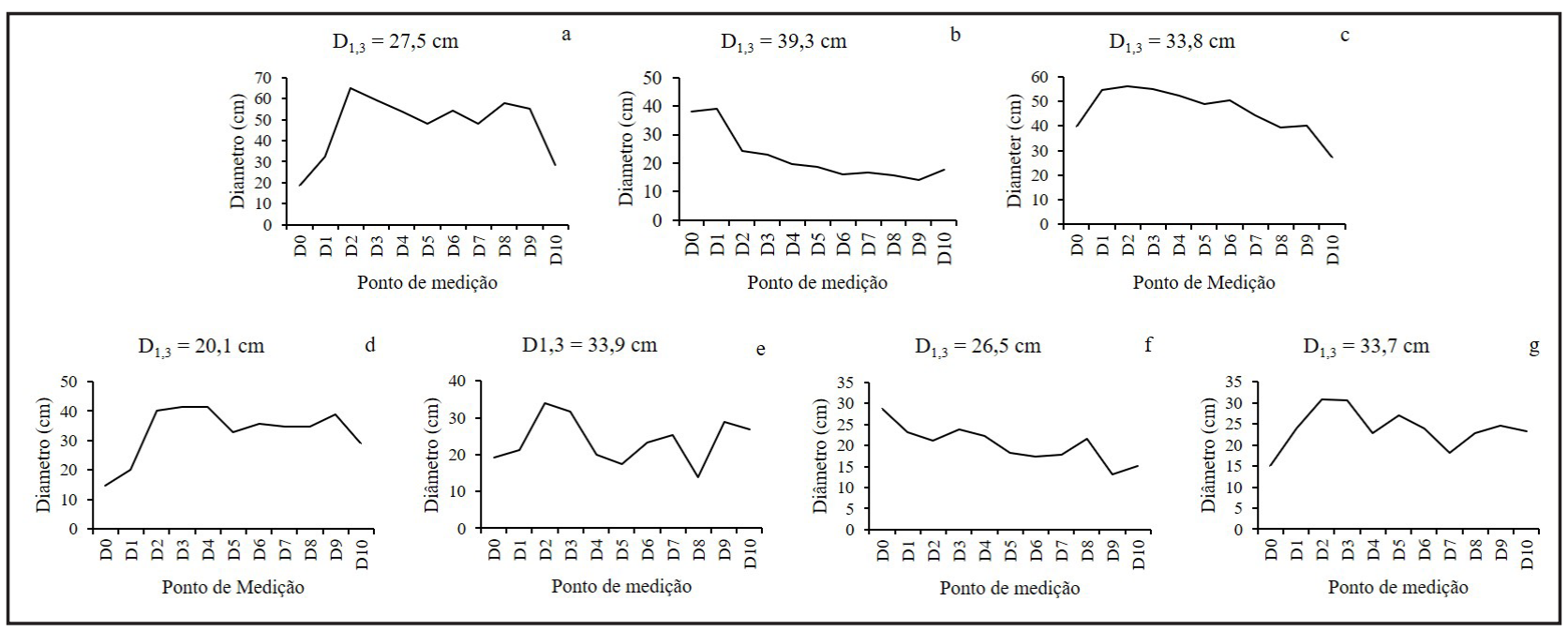

Fonte: Autores (2021)

O exemplo ilustrado na Figura 4 a mostra um caso em que $D_{1,3}$ é bem menor que os diâmetros medidos ao longo do fuste, ocasionando uma subestimativa no volume; exemplos semelhantes são verificados nas Figuras 4c e 4d. No exemplo mostrado na Figura 4b, apesar de seguir um esperado decréscimo dos diâmetros ao longo do fuste, esse decréscimo ocorre de forma abrupta, proporcionando uma superestimativa 
do volume ao considerar o diâmetro de referência desse tronco. Os demais perfis exemplificam a oscilação entre diâmetros ao longo do tronco (Figura 4e, 4f, 4g).

Em uma análise conjunta de todos os resultados apresentados, o volume da necromassa em troncos caídos é modelado com melhor precisão aplicando-se Redes Neurais Artificiais. Entretanto, esse método apresentou falhas ao ser extrapolado para uma base de dados diferente da utilizada no treinamento. Com isso, o ajuste do modelo de Shumacher-Hall por regressão não linear mostrou desempenho satisfatório, em especial para a floresta não manejada, uma vez que essa área apresentou menor variação nos dados, com destaque para a base de dados selecionada para teste (Tabela 2), reduzindo erros de estimativa. Dessa forma, as estimativas de volume de necromassa para floresta manejada e floresta não manejada na Amazônia Central podem ser feitas aplicando as Equações (5) e (6), respectivamente:

$$
\begin{aligned}
& \mathrm{V}_{\mathrm{n}}=0,000113 \times \mathrm{D}_{1,3}^{1,908118} \times \mathrm{L}^{0,898074} \\
& \mathrm{~V}_{\mathrm{n}}=0,000106 \times \mathrm{D}_{1,3}^{1,997987} \times \mathrm{L}^{0,792492}
\end{aligned}
$$

Em que: $V_{n}=$ Volume de necromassa $\left(m^{3}\right) ; D_{1,3}=$ Diâmetro a 1,30 $\mathrm{m}$ da base do tronco $(\mathrm{cm}) ; \mathrm{L}=$ Comprimento do tronco $(\mathrm{m})$.

\section{CONCLUSÕES}

A modelagem do volume individual da necromassa em troncos mortos caídos apresenta grande dificuldade para a minimização dos erros de estimativa devido às características dos dados. Os resultados mais satisfatórios foram obtidos por meio do ajuste do modelo de Schumacher-Hall por regressão não linear. Considerando a necromassa um importante componente do estoque de carbono em uma floresta, os erros de estimativas proporcionado pelas técnicas aplicadas são menos relevantes que a não quantificação desses dados em campo. Diante disso, recomenda-se a busca contínua da incorporação deste componente da vegetação em estudos em florestas tropicais, em especial os direcionados ao estoque de carbono. 


\section{REFERÊNCIAS}

AGUIAR, D. R. et al. Adjustment of volumetric equations from fallen trees for analysis of the logging effect in the Tapajós National Forest, Pará, Brazil. Australian Journal of Basic and Applied Sciences, [s. I.], v. 11, n. 10, p. 48-59, 2017.

ANTONIO, I. C. Boletim agrometeorológico série anual: 2016: Estação Agroclimatológica da Embrapa Amazônia Ocidental na Rodovia AM-010, Km 29. [S. I.]: Embrapa Amazônia Ocidental, 2017. 60 p.

ARAÚJO, A. C. S. C. et al. Artificial Neural Networks with Skip Layer connections to estimate the volume of forest formations in the state of Minas Gerais. Australian Journal of Basic and Applied Sciences, [s. I.], v. 9, n. 36, p. 319-327, 2015.

BACCINI, A. et al. Estimated carbon dioxide emissions from tropical deforestation improved by carbon-density maps. Nature Climate Change, London, v. 2, p. 182-185, 2012.

COSTA FILHO, S. V. S. et al. Configuração de algoritmos de aprendizado de máquina na modelagem florestal: um estudo de caso na modelagem da relação hipsométrica. Ciência Florestal, Santa Maria, v. 29, n. 4, p. 1501-1515, 2019.

CHANG; C.; LIN, C. LIBSVM: a library for support vector machines. ACM Transactions on Intelligent Systems and Technology. 2:27:1--27:27. [S. I.: s. n.], 2011. Disponível em: http://www. csie.ntu.edu.tw/ cjlin/libsvm. Access: 20 abr. 2021.

CRUZ FILHO, D.; SILVA, J. N. M. Avaliação da quantidade de resíduos lenhosos em floresta não explorada e explorada com técnicas de redução de impactos, utilizando amostragem por linha interceptadora, no Médio Moju, Amazônia Oriental, Brasil. Acta Amazonica, Manaus, v. 39, n. 3, p. 527-532, 2009.

EGGLESTON, H. S. et al. Guidelines for National Greenhouse Gas Inventories. [S. I.]: IGES, 2006. v. 4.

FRAVER, S. et al. Woody debris volume depletion through decay: implications for biomass and carbon accounting. Ecosystems, [s. I.], v. 16, n. 7, p. 1262-1272, 2013.

FREITAS, F. C. Estoque de necromassa em floresta não manejada e manejada no estado do Amazonas. 2017. Dissertação (Mestrado em Ciências Florestais e Ambientais) - Universidade Federal do Amazonas, Manaus, 2017.

FREITAS, F. C.; AZEVEDO, C. P.; SOUZA, C. R. Estoque de necromassa em floresta não manejada e floresta manejada na Amazônia Central. Scientia Forestalis, Piracicaba, v. 47, n. 121, p. 1323, 2019.

GIMENEZ, B. O. et al. Equações volumétricas para espécies comerciais madeireiras do sul do estado de Roraima. Scientia Forestalis, Piracicaba, v. 43, n. 106, p. 291-301, 2015. 
HAYKIN, S. Redes neurais: princípios e prática. 2. ed. Porto Alegre: Bookman, 2001. 900 p.

HÉRAULT, B. et al. Modeling decay rates of dead wood in a neotropical forest. Oecologia, Berlin, v. 164, n. 1, p. 243-251, 2010.

HIGUCHI, F. G. et al. The use of Natural Fallen Trees in Mature Tropical Amazonian Forest for Volumetric Regression Analysis and Volume Equations Adjustment. Australian Journal of Basic and Applied Sciences, [s. I.], v. 9, n. 31, p. 342-348, 2015.

IBGE. Manual técnico da vegetação brasileira: sistema fitogeográfico, inventário das formações florestais e campestres, técnicas e manejo de coleções botânicas, procedimentos para mapeamentos. [S. I.], 2012. 271 p.

IBGE. Manual técnico de pedologia. [S. I.], 2015. 430 p.

LASSAUCE, A. et al. Deadwood as a surrogate for forest biodiversity: meta-analysis of correlations between deadwood volume and species richness of saproxylic organisms. Ecological Indicators, [s. I.], v. 11, n. 5, p. 1027-1039, 2011.

LIMA, A. J. N. Avaliação de um sistema de inventário florestal contínuo em áreas manejadas e não manejadas do estado do Amazonas. 2010. Tese (Doutorado em Ciências de Florestas Tropicais) - Instituto Nacional de Pesquisas da Amazônia, Manaus, 2010.

MIGUEL, E. P. et al. Redes neurais artificiais para a modelagem do volume de madeira e biomassa do cerradão com dados de satélite. Pesquisa Agropecuaria Brasileira, Brasília, v. 50, n. 9, p. 829-839, 2015.

MOREIRA, A. B.; GREGOIRE, T. G.; COUTO, H. T. Z. Estimation of the volume, biomass and carbon content of coarse woody debris within two forest types in the State of São Paulo, Brazil. Forestry, Edimburgo, v. 92, n. 3, p. 278-286, 2019a.

MOREIRA, A. B.; GREGOIRE, T. G.; COUTO, H. T. Z. Wood density and carbon concentration of coarse woody debris in native forests, Brazil. Forest Ecosystems, [s. I.], v. 6, n. 1, p. 6-18, 2019b.

ÖZÇELIK, R. et al. Estimating tree bole volume using artificial neural network models for four species in Turkey. Journal of Environmental Management, London, v. 91, n. 3, p. 742-753, 2010.

PALACE, M. et al. A Review of Above Ground Necromass in Tropical Forests. In: SUDARSHANA, P.; NAGESWARA-RAO, M.; SONEJI, J. R. Tropical Forests. [S. I.]: Intech, 2012. p. 215-252.

PAN, Y. et al. A large and persistent carbon sink in the world's Forests. Science, [s. I.], v. 333, p. 988-993, 2011.

PIPONIOT, C. et al. Carbon recovery dynamics following disturbance by selective logging in Amazonian forests. eLife, Cambridge, v. 5, 2016.

RIBEIRO, R. B. S.; GAMA, J. R. V.; MELO, L. O. Seccionamento para cubagem e escolha de equações de volume para a Floresta Nacional do Tapajós. Cerne, Lavras, v. 20, n. 4, p. 605612, 2014. 
RUSSELL, B. M. et al. Quantifying carbon stores and decomposition in dead wood: a review. Forest Ecology and Management, Amsterdam, v. 350, p. 107-128, 2015.

RUSSELL, M. B. et al. Residence Times and Decay Rates of Downed Woody Debris Biomass/ Carbon in Eastern US Forests. Ecosystems, [s. I.], n. 17, p. 765-777, 2014.

SAATCHI, S. S. et al. Benchmark map of forest carbon stocks in tropical regions across three continents. PNAS, Washington, v. 108, n. 24, p. 9899-9904, 2011.

SCARANELLO, M. A. S. et al. Estimation of coarse dead wood stocks in intact and degraded forests in the Brazilian Amazon using airborne lidar. Biogeosciences, [s. I.], v. 16, n. 17, p. 3457-3474, 2019.

SOUZA, C. R. et al. Dinâmica e estoque de carbono em floresta primária na região de Manaus/ AM. Acta Amazonica, Manaus, v. 42, n. 4, p. 501-506, 2012.

SOUZA, M. A. S. et al. Dinâmica e produção de uma floresta sob regime de manejo sustentável na Amazônia Central. Floresta, Curitiba, v. 47, n. 1, p. 55-63, 2017.

SPIES, T. A. Forest structure: a key to the ecosystem. Northwest Science, Washington, v. 72, n. 2, 1998.

STEINWART, I.; CHRISTMANN, A. Support vector machines. [S. I.]: Springer, 2008. 466 p.

STOKLAND, J. N.; SIITONEN, J.; JONSSON, B. G. Biodiversity in dead wood. Cambridge: Cambridge University Press, 2012. 509 p.

TONINI, H.; BORGES, R. A. Equação de volume para espécies comerciais em Floresta Ombrófila Densa no sul de Roraima. Pesquisa Florestal Brasileira, Colombo, v. 35, n. 82, p. 111-117, 2015.

UMNOUYSIN, S.; SANGTIEAN, T.; POUNGPARN, S. Zonal distribution of coarse woody debris and its contribution to net primary production in a secondary mangrove forest. Ecological Research, Kyoto, v. 32, n. 1, p. 51-60, 2017.

ZANINOVICH, S. C.; FONTANA, J. L.; GATTI, M. G. Atlantic Forest replacement by nonnative tree plantations: comparing aboveground necromassa between native forest and pine plantation ecosystems. Forest Ecology and Management, Amsterdam, v. 363, p. 39-46, 2016. 


\section{Contribuição de Autoria}

\section{1 - Filipe Campos de Freitas}

Engenheiro Florestal, Me., Doutorando

https://orcid.org/0000-0002-5362-7486• filipe.freitas19@gmail.com

Contribuição: Curadoria de dados, Análise Formal, Investigação, Escrita - primeira redação, Escrita - revisão e edição

\section{2 - Daniel Dantas}

Engenheiro Florestal, Me., Doutorando

https://orcid.org/0000-0002-7928-9155•dantasdaniel12@yahoo.com.br

Contribuição: Curadoria de dados, Análise Formal, Escrita - primeira redação

\section{3 - Celso Paulo de Azevedo}

Engenheiro Florestal, Dr., Pesquisador

https://orcid.org/0000-0002-3172-4939• celso.azevedo1958@gmail.com

Contribuição: Conceituação, Supervisão, Administração do projeto

\section{4 - Cintia Rodrigues de Souza}

Engenheiro Florestal, Dr., Pesquisador

https://orcid.org/0000-0002-4556-3101・cintia.souza@embrapa.br

Contribuição: Obtenção de financiamento, Supervisão, Administração do projeto

\section{5 - Natalino Calegario}

Engenheiro Florestal, Dr., Professor

https://orcid.org/0000-0001-8323-1223•calegari@ufla.br

Contribuição: Conceituação, Análise Formal

\section{Como citar este artigo}

Freitas, F. C.; Dantas, D.; Azevedo, C. P.; Souza, C. R.; Calegario, N. Modelagem volumétrica da necromassa lenhosa em floresta manejada e não manejada na Amazônia Central. Ciência Florestal, Santa Maria, v. 31, n. 4, p. 1812-1832, 2021. DOI 10.5902/1980509848108. Disponível em: https://doi.org/10.5902/1980509848108. 